\title{
Is Moderate Intensity Exercise during Pregnancy Safe for the Fetus? An Open Clinical Trial
}

\section{Exercício de intensidade moderada durante a gravidez é seguro para o feto? Ensaio clínico aberto}

\author{
Adriana Suely Oliveira Melo ${ }^{1}$ João Luiz Pinto e Silva ${ }^{2}$ Fabiana de Oliveira Melo ${ }^{1}$ \\ Emanuela Santos Barros ${ }^{1}$ Hugo Leonardo Santos ${ }^{1}$ Melania Maria Ramos Amorim ${ }^{1,3,4}$ \\ Alex Sandro Rolland Souza ${ }^{1,3,5,6(0)}$
}

${ }^{1}$ Instituto de Pesquisa Professor Joaquim Amorim Neto, Campina

Address for correspondence Alex Sandro Rolland Souza, MD, PhD, Grande, PB, Brazil

2 Universidade Estadual de Campinas, Campinas, SP, Brazil Rua Salvino Oliveira Neto, 87, 58402-040, Campina Grande, PB, Brasil

3 Instituto de Medicina Integral Prof. Fernando Figueira, Recife, PE, Brazil (e-mail: alexrolland@uol.com.br).

${ }^{4}$ Universidade Federal de Campina Grande, Campina Grande, Brazil

${ }^{5}$ Universidade Federal de Pernambuco, Recife, PE, Brazil

6 Universidade Católica de Pernambuco, Recife, PE, Brazil

Rev Bras Ginecol Obstet 2019;41:531-538.

\section{Resumo \\ Palavras-chave \\ - cardiotocografia \\ - frequência cardíaca fetal \\ - caminhada \\ - exercício \\ - gravidez}

Objetivo Determinar o efeito da caminhada em esteira sobre a frequência cardíaca materna (FCM) e parâmetros cardiotocográficos (batimentos cardiofetais basais [BCFs], movimentos ativos fetais [MAFs], número de acelerações e desacelerações e variabilidade de curta [STV] e longa [LTV] duração da frequência cardíaca fetal) em gestantes na $36^{\text {a }}$ semana.

Métodos Foi realizado um ensaio clínico não randomizado e aberto com 88 gestantes saudáveis submetidas a caminhada de moderada intensidade na esteira e a cardiotocografia computadoriza em 3 momentos de 20 minutos (antes, durante e após a caminhada).

Resultados A média dos BCFs diminuiu durante a caminhada, retornando a níveis prévios (antes: 137 bpm; durante: 98 bpm; após: 140 bpm; $p<0,001$ ), com bradicardia ocorrendo em $56 \%$ dos fetos nos primeiros 10 minutos do exercício, e em $47 \%$ após 20 minutos. A bradicardia fetal não foi observada em outros momentos (antes ou depois). As médias da STV e da LTV foram 7,9, 17,0 e 8,0 milissegundos ( $p<0,001)$ e 7,6, 10,7 e 7,6 bpm $(p=0,002)$ antes, durante e após a caminhada, respectivamente. A média dos números dos MAFs em 1 hora foi 29,9, 22,2 e 45,5, respectivamente, nos três momentos $(p<0,001)$. Nas mulheres com sobrepeso/obesidade, a média da FCM foi menor $(p=0,02)$. Após a análise de regressão logística, duas variáveis permaneceram significativamente associadas a bradicardia: aptidão maternal na $28^{\text {a }}$ semana de gravidez (efeito protetor) e peso materno (aumento do risco).

(D) Alex Sandro Rolland Souza's ORCID is https://orcid.org/00000001-7039-2052.

received

October 23, 2018

accepted

August 6, 2019
DOI https://doi.org/

10.1055/s-0039-1697035. ISSN 0100-7203.
Copyright $(2019$ by Thieme Revinter

Publicações Ltda, Rio de Janeiro, Brazil
License terms

(c) (1) 
Conclusão Em fetos saudáveis, o exercício físico mostrou-se seguro, uma vez que, embora os BCFs e os MAFs diminuam durante a caminhada na esteira, foi observado um aumento da SVT e da LTV.

Abstract

Keywords
- cardiotocography
- fetal heart rate
- walking
- exercise
- pregnancy

Objective To determine the effect of treadmill walking on maternal heart rate (MHR) and cardiotocographic parameters (basal fetal heart rate [FHR], active fetal movements [AFM], number of accelerations and decelerations, and short-term variation [STV] and long-term variation [LTV] of fetal heart rate) in pregnant women at 36 weeks.

Methods A nonrandomized, open clinical trial involving 88 healthy pregnant women submitted to moderate intensity walking and computed cardiotocography in 320 minute periods (resting, treadmill walking, and postexercise recovery).

Results The mean FHR decreased during walking (resting: 137 bpm; treadmill: 98 bpm; recovery: $140 \mathrm{bpm} ; p<0.001$ ), with bradycardia occurring in $56 \%$ of the fetuses in the first 10 minutes of exercise, and in $47 \%$ after 20 minutes. Bradycardia was not detected in the other phases. The mean STV and HV were 7.9, 17.0, and 8.0 milliseconds $(p<0.001)$ and 7.6, 10.8 and $7.6 \mathrm{bpm}(p=0.002)$ in the resting, walking and recovery phases, respectively. The mean number of fetal movements in 1 hour was 29.9, 22.2 and 45.5, respectively, in the 3 periods $(p<0.001)$. In overweight/obese women, the mean FHR was lower $(p=0.02)$. Following the logistic regression analysis, two variables remained significantly associated with bradycardia: maternal fitness in the $28^{\text {th }}$ week of pregnancy (protective effect) and maternal weight (increased risk). Conclusion In healthy fetuses, physical exercise proved to be safe, since, although FHR and AFM decreased during treadmill walking, an increase in SVT and LTV was observed.

\section{Introduction}

The practice of physical exercise is stimulated during pregnancy as a way of controlling excessive weight gain and reducing the risk of developing diseases such as preeclampsia and gestational diabetes, in addition to improving the physical fitness and well-being of the woman. ${ }^{1,2}$ Nevertheless, interest in the effects of physical exercise in pregnancy focuses not only on the mid-and long-term adaptive changes that are present in other phases of life. There is also a concern with respect to the acute effects, since no consensus has yet been reached on the physiological changes in fetoplacental blood flow and the consequent fetal responses that take place during exercise, due the difficulty involved in measuring these factors. ${ }^{3-7}$

Studies using animal models suggest that, during the practice of physical exercise, there is a redistribution of cardiac output, with an increase in flow to the muscles and skin and a reduction in flow to the viscera in response to the greater metabolic demand of the muscles in activity. This response also results in a reduction of $\sim 35 \%$ in the uteroplacental blood flow. ${ }^{8,9}$ As a protective mechanism, an increase occurs in blood flow to the placenta in detriment to the myometrium, hemoconcentration develops, and there is a greater affinity of fetal blood for oxygen. The reduction in blood flow is directly proportional to the intensity of the exercise and to the muscle mass used. Once exercise stops, blood flow quickly returns to normal. ${ }^{8,9}$

Alterations also occur in the fetal heart rate (FHR) during exercise, and tachycardia may occur in response to transient hypoxia. ${ }^{10-12}$ This protective mechanism facilitates the trans- ference of oxygen through the placenta, reducing partial $\mathrm{CO}_{2}$ pressure. Transient bradycardia may also occur after exercise has finished, probably as the result of a fetal or maternal vagal reflex. ${ }^{10-12}$ Therefore, based on this lack of agreement between studies regarding the occurrence of alterations in the FHR, our hypothesis is that the drop in FHR during physical exercise ${ }^{10-12}$ occurs together with compensatory mechanisms in the fetus that ultimately maintain normoxemia. ${ }^{3-5,8,9}$

Since walking is inexpensive, accessible, and easily performed, it is a common form of physical exercise performed by pregnant women. Walking is also simple to reproduce in clinical practice. ${ }^{5}$ The American College of Obstetricians and Gynecologists (ACOG) recommends the practice of physical exercise during pregnancy, suggesting that walking is not only safe, but also effective in reducing maternal and fetal risks. ${ }^{2,13}$

The objective of the present study was to evaluate the effect of moderate intensity walking in low-risk pregnant women, performed in accordance with the recommendations of the ACOG. ${ }^{13}$ In addition, fetal heart rate (FHR) (bradycardia and tachycardia) and maternal heart rate (MHR), fetal movements (FM), short-term variation (STV), transient episodes of acceleration (TA), deceleration, and high FHR variability were assessed. Factors associated with the occurrence of fetal bradycardia were also evaluated.

\section{Methods}

This was an open clinical trial with no control group, nested within a larger project entitled "Physical exercise and 
gestational and perinatal outcomes: a randomized, controlled trial." The trial involved pregnant women attending basic healthcare units in the city of Campina Grande, state of Paraíba, Brazil, between May 2008 and September 2012. The participants were followed-up at 13,20 and 28 weeks of pregnancy. The study was approved by the internal review board of the Universidade Estadual da Paraíba (approval letter 0323.0.133.000-07) and registered at clinicaltrials. gov (NCT00641550). All of the participants signed an informed consent form prior to admission to the study.

The sample size was calculated using the Open Epi software, version 2.1. Based on an incidence of fetal bradycardia of $63 \%$ detected in a group of women who initiated treadmill walking, ${ }^{6}$ and for a power of $80 \%$ and a significance level of $5 \%$, the total sample was calculated as 90 pregnant women.

A subsample was formed of the first 90 women selected for participation in the larger project, and these women were submitted to treadmill walking on an Athletic treadmill (Athletic, Joinville, SC, Brazil) when they were in the $36^{\text {th }}$ week of pregnancy. The intervention consisted of moderate-intensity walking 3 times a week. The initial duration of walking was 15 minutes, gradually increasing over the study period in accordance with the previous physical fitness level of the woman. Prior to beginning the exercise, the women performed 5 minutes of warming-up and stretching exercises.

The primary objective was not to conduct a stress test, but to reproduce moderate-intensity walking according to the ACOG recommendations for pregnant women. ${ }^{13}$ Treadmill walking was chosen instead of outdoors walking to enable the FHR to be monitored by cardiotocography (CTG). During the examinations performed at baseline and in the recovery phase, CTG was performed with the woman in the dorsal decubitus position, inclined at 45 degrees. The MHR was monitored using a Polar S120 heart rate monitor (Polar, Kempele, Finland). Arterial blood pressure was measured according to the recommendations of the Brazilian College of Cardiology immediately prior to and immediately following exercise, using a Tycos Ds66 mobile aneroid sphygmomanometer (Welch Allyn, Skaneateles Falls, NY) and a Tycos stethoscope (Welch Allyn, Skaneateles Falls, NY).

Due to the paucity of studies that included a three-phase evaluation (baseline, exercise and recovery phases) of women submitted to moderate treadmill walking, a pilot study was conducted on the first 90 women, 88 of whom were considered eligible and who agreed to participate in the test. After analysis, the sample size was found to be sufficient to show statistically significant differences in the main variables evaluated.

The inclusion criteria consisted of having participated in the main project. Therefore, all of the women had previously met the inclusion criteria for the main study of being sedentary and bearing a single and live fetus with a gestational age $\leq$ 13 weeks. Sedentariness was defined as metabolic equivalent of task $(\mathrm{MET})<1.5$. The level of physical activity was evaluated using the Pregnancy Physical Activity Questionnaire (PPAQ). ${ }^{14}$ Smokers, women with chronic diseases, premature rupture of membranes, women in premature labor, preeclampsia, fetal distress, and the occurrence of major fetal anomalies or fetal losses comprised the exclusion criteria.

All of the women were submitted to computed cardiotocography (CTGc), using a Sonicaid 8002 device (Sonicaid, Oxford, UK), for a period of 60 minutes divided into 3 periods of 20 minutes: baseline, treadmill walking, and a recovery period. After every 20 minutes, the parameters of interest were extracted from the report issued by the computed system in accordance with the criteria established by Dawes and Reedman. ${ }^{15}$

Walking was considered to be at moderate intensity when the MHR during exercise remained between $60 \%$ and $80 \%$ of the maximum heart rate (HR) corrected for age ${ }^{16}$ In addition, subjective perceived exertion was measured using the Borg scale, ${ }^{17}$ respecting the previously established limitations of each individual woman. During the walking phase, a sonar device and a tocodynamometer were attached to the women, at the highest area of FHR auscultation and at the uterine fundus, respectively, using adhesive tape. Ultrasonography was used to confirm fetal cardiac focus, and the CTGc was performed in the morning, 30 minutes after a light meal.

The following outcome variables were evaluated: FHR, MHR, fetal movements, STV, episodes of high FHR variability, FHR signal loss, and frequency of bradycardia, tachycardia, transient accelerations and decelerations. Deceleration and acceleration were defined as a decrease or increase of $15 \mathrm{bpm}$ in the FHR for at least 15 seconds. Bradycardia was defined as FHR $<110 \mathrm{bpm}$, and tachycardia as FHR $>160 \mathrm{bpm}$ for at least 10 minutes. ${ }^{18}$ Short-term variation corresponds to the variation in bpm between each fetal heart beat, and its evaluation was only possible using the computer system. ${ }^{15}$ Fetal movements were recorded using an event-marking device attached to a cardiotocograph operated by the pregnant woman. The woman was instructed to press the device every time she perceived a fetal movement. The percentage of FHR signal loss in each phase was obtained from the report supplied by the system.

To characterize the sample, a questionnaire was applied in the $13^{\text {th }}$ week of pregnancy to assess socioeconomic and obstetric factors. The women were weighed at the $13^{\text {th }}$ and $36^{\text {th }}$ weeks on a Tanita digital scale (Tanita, Tokyo, Japan). Weight gain was calculated from the difference in the weights obtained. Height was measured at the $13^{\text {th }}$ week using a Seca stadiometer (Seca, Chiba, Japan). Body mass index (BMI) was calculated using the following formula: weight $(\mathrm{kg}) /$ height $^{2}(\mathrm{~m})$, and the women were classified as overweight or obese according to the criteria established by Atallah for 36 weeks of pregnancy. ${ }^{19}$ Peak oxygen consumption $\left(\mathrm{VO}_{2 \text { peak }}\right)$ was calculated by progressive testing on a treadmill at the $13^{\text {th }}, 20^{\text {th }}$ and $28^{\text {th }}$ weeks of pregnancy, with these data having been obtained from the larger project. ${ }^{20}$ In the $36^{\text {th }}$ week of pregnancy, ultrasonography was also performed to estimate fetal weight using a Voluson expert scanner (GE Healthcare, Chicago, IL, USA).

The Epi Info software version 7 (Centers for Disease Control and Prevention, Atlanta, GA, USA) and MedCalc, version 12.5.0 (MedCalc Software, Ostend, Belgium) were 
used in the statistical analysis. Logarithmic transformation was used in absence of normality of the distribution of the numerical variables, determined by the Kolmogorov-Smirnov test. Accelerations, decelerations, episodes of high variability, MHR, FHR and STV were analyzed as discrete variables. Signal loss was evaluated as a continuous variable. The categorical variables were analyzed using their frequency of distribution. Measures of central tendency and dispersion were calculated for the numerical variables. The repeated measures analyses of variance (ANOVA) was used to compare the mean basal FHR and STV prior to, during, and after walking. Finally, the frequency of bradycardia was determined. To evaluate the association between bradycardia and the numerical variables, ANOVA (continuous variables) and the Kruskal-Wallis tests were used (discrete variables and for the continuous variables when the distribution was not normal). Next, stepwise multiple logistic regression analysis was performed to identify the main factors associated with the occurrence of bradycardia. The outcome bradycardia was categorized as: 1 (present) or 0 (absent), and the continuous predictive variables taken into consideration were: maternal weight, maternal weight gain, fetal weight at the $36^{\text {th }}$ week, $\mathrm{VO}_{2 \text { peak }}$ at the $13^{\text {th }}, 20^{\text {th }}$ and $28^{\text {th }}$ weeks, maternal height, and systolic arterial pressure measured after 20 minutes of walking. The variables included in this model were those with a significance level of $20 \%$ in the bivariate analysis. Adjusted odds ratios (ORs) and their 95\% confidence intervals (CI) were calculated. P-values $<0.05$ were considered statistically significant throughout the entire statistical analysis.

\section{Results}

A total of 88 pregnant women were included in the study. The mean age of the women was $25 \pm 6$ years old, and they had a median of 9 years of schooling (range: 1-17 years). Most of the women described themselves as brown-skinned (43\%), mentioned a per capita family income of up to 3 current minimum wages (56\%), and were in paid employment at the time (67\%). Most patients were nulliparous (53\%).

In the $36^{\text {th }}$ week of pregnancy, the mean maternal weight was $69 \pm 10 \mathrm{~kg}$, with $40 \%$ of the women being classified as obese/overweight. The mean estimated fetal weight was $2,840 \pm 233 \mathrm{~g}$. The mean FHR was lower in overweight/obese pregnant women than in normal/low weight $(98 \pm 9.3$ vs $103 \pm 7.7 \mathrm{bpm}, p=0.02$ ). No difference was found in FHR signal loss between the three phases (CTGc at baseline, 4\%; during treadmill walking, $7 \%$; and in the recovery phase, $4 \%$; $p=0.80$ ). All of the women completed the 60 -minute monitoring period without any problem that would have justified their discontinuation.

The mean FHR was $137 \pm 8.4 \mathrm{bpm}$ at baseline, $98 \pm 13.1$ bpm during walking, and $140 \pm 9.2 \mathrm{bpm}$ in the recovery phase, with a statistically significant difference between

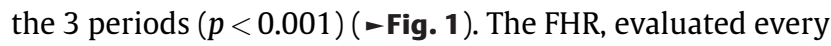
5 minutes, showed a decrease immediately after beginning walking that persisted throughout the entire exercise period. Shortly after the end of the exercise, the FHR rapidly returned

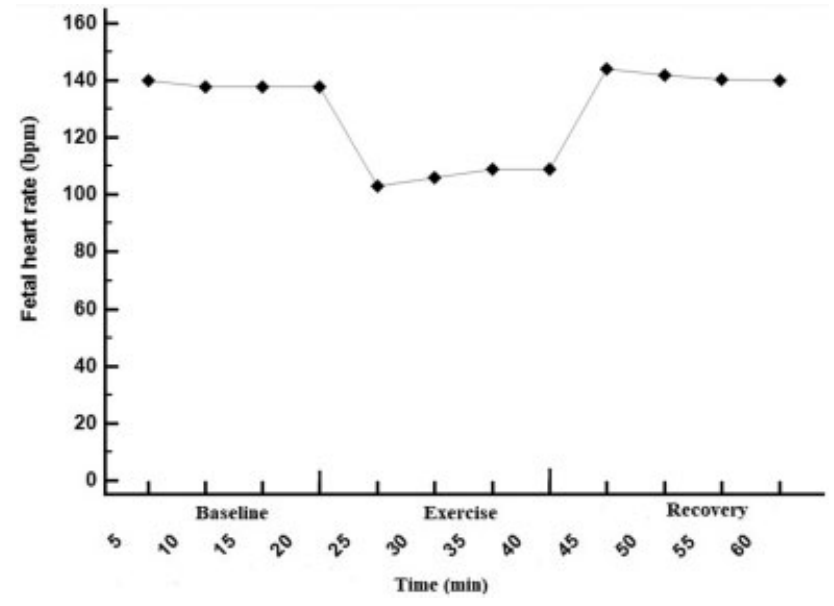

Fig. 1 Changes in mean basal fetal heart rate (FHR) as monitored at baseline, during exercise and during recovery after treadmill walking at moderate intensity. The mean basal FHR was $137 \pm 8.4 \mathrm{bpm}$ at baseline, $98 \pm 13.1 \mathrm{bpm}$ during exercise, and $140 \pm 9.2 \mathrm{bpm}$ in the recovery phase $(p<0.001)$.

to normal $(p<0.001)$. The mean STV and HV were $7.9 \pm 2.5$, $17.0 \pm 6.3$, and $8.0 \pm 2.8$ milliseconds $(p<0.001)$; and $7.6 \pm 6.4,10.8 \pm 7.8$, and $7.6 \pm 6.4 \mathrm{bpm}(p=0.002)$ in the resting, walking, and recovery phases, respectively (-Fig. 2). The mean number of fetal movements in 1 hour was $29.9 \pm 30.7,22.2 \pm 39.1$, and $45.5 \pm 42.3$, respectively, in the 3 periods $(p<0.001)$.

None of the fetuses presented tachycardia in any of the 3 phases, and bradycardia was found in $56 \%$ of the fetuses in the first 10 minutes of exercise, and in $47 \%$ after 20 minutes. Bradycardia was not detected in the other phases. The mean MHR was $88 \pm 11.4 \mathrm{bpm}$ at baseline, $121 \pm 10.3 \mathrm{bpm}$ during walking, and $92 \pm 14.3 \mathrm{bpm}$ in the recovery period $(p<0.001)$.

Regarding the frequency of decelerations and transient accelerations, no differences were found between the 3 phases in which CTGc was performed, neither in the median number of transient accelerations $(3,2$, and $3 ; p=0.16)$ nor in the median number of decelerations $(0,1$, and 0 ; $p=0.18$ ).

Of the variables evaluated, an association was found between bradycardia and systolic arterial pressure at the end of the exercise $(p=0.04)$, physical fitness evaluated in the $28^{\text {th }}$ week of pregnancy ( $p=0.002)$, and maternal weight at the $36^{\text {th }}$ week of pregnancy ( $p=0.015$ ) ( - Table 1$)$. The variables that remained significantly associated with fetal bradycardia in the exercise phase were physical fitness at the $28^{\text {th }}$ week, which was associated with a reduced risk of bradycardia $(\mathrm{OR}=0.25$; 95\%CI: 0.06-0.98), and maternal weight at the $36^{\text {th }}$ week of pregnancy, which was associated with an increased risk (OR =4.07; 95\%CI: 1.15-14.1) (-Table 2).

\section{Discussion}

The results of the present study show that moderate-intensity walking resulted in alterations in the MHR and in the FHR, with a high percentage of fetal bradycardia during the 

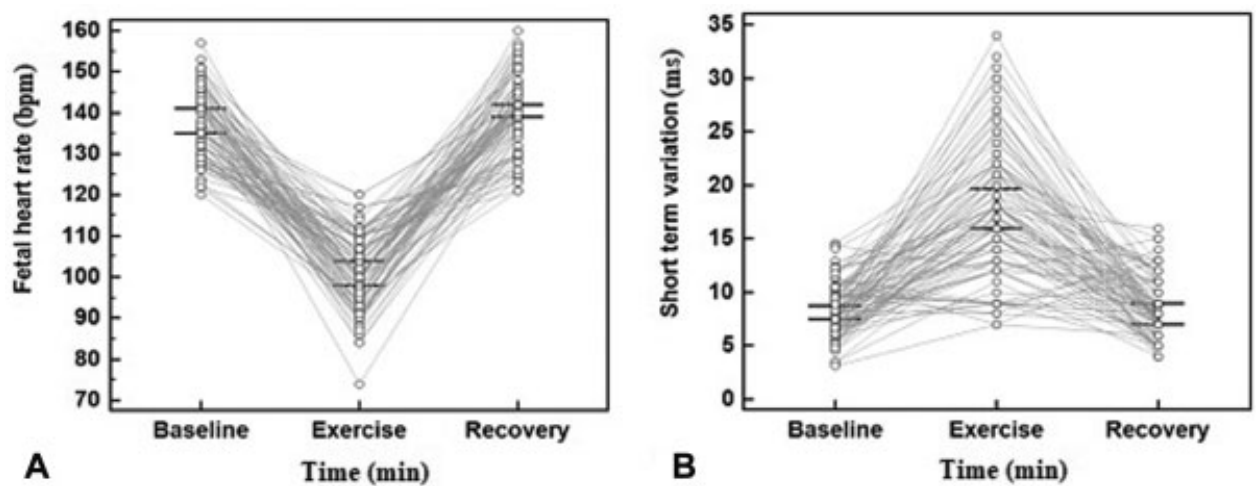

Fig. 2 (A) Means basal fetal heart rate (FHR) and (B) means short-term variability (STV) in the three phases in which cardiotocography was performed (at baseline, during treadmill exercise, and in the recovery period). The mean basal FHR was $137 \pm 8.4 \mathrm{bpm}$ at baseline, $98 \pm 13.1 \mathrm{bpm}$ during exercise, and $140 \pm 9.2 \mathrm{bpm}$ in the recovery phase $(p<0.001)$. The STV was $7.9 \pm 2.5$ milliseconds at baseline, $17.0 \pm 6.3$ milliseconds in the exercise phase, and $8.0 \pm 2.8$ milliseconds in the recovery phase $(p<0.001)$.

Table 1 Factors associated with bradycardia during moderateintensity walking

\begin{tabular}{|c|c|c|c|}
\hline & \multicolumn{2}{|l|}{ Bradycardia } & \multirow[t]{2}{*}{ p-value } \\
\hline & Yes & No & \\
\hline $\begin{array}{l}\text { Age, years } \\
(\text { mean } \pm S D)\end{array}$ & $24.4 \pm 6.7$ & $24.7 \pm 6.3$ & 0.81 \\
\hline $\begin{array}{l}\text { Systolic blood } \\
\text { pressure at the } \\
\text { end of exercise, } \mathrm{mmHg} \\
\text { (median; range) }\end{array}$ & $104 ; 110-90$ & $114 ; 120-100$ & 0.04 \\
\hline $\begin{array}{l}\text { Diastolic blood } \\
\text { pressure at the } \\
\text { end of exercise, } \mathrm{mmHg} \\
\text { (median; range) }\end{array}$ & $67 ; 80-50$ & $67 ; 80-55$ & 0.91 \\
\hline $\begin{array}{l}\text { Maternal height, } \\
\mathrm{m} \text { (mean } \pm \mathrm{SD} \text { ) }\end{array}$ & $1.55 \pm 0.06$ & $1.58 \pm 0.07$ & 0.18 \\
\hline $\begin{array}{l}\text { Maternal weight at } \\
36 \text { weeks, } \\
\mathrm{kg}(\text { mean } \pm \text { SD) }\end{array}$ & $70.1 \pm 10.6$ & $63.3 \pm 7.2$ & 0.015 \\
\hline $\begin{array}{l}\mathrm{VO}_{\text {2peak }} \text { at } 13 \text { weeks } \\
(\text { mean } \pm \text { SD })\end{array}$ & $28.7 \pm 3.91$ & $30.6 \pm 3.25$ & 0.06 \\
\hline $\begin{array}{l}\mathrm{VO}_{\text {2peak }} \text { at } 20 \text { weeks } \\
(\text { mean } \pm \text { SD) }\end{array}$ & $29.9 \pm 3.23$ & $31.1 \pm 2.36$ & 0.19 \\
\hline $\begin{array}{l}\mathrm{VO}_{\text {2peak }} \text { at } 28 \text { weeks } \\
(\text { mean } \pm \text { SD) }\end{array}$ & $27.6 \pm 3.5$ & $30.4 \pm 2.4$ & 0.002 \\
\hline $\begin{array}{l}\text { BMI at } 36 \text { weeks, } \mathrm{kg} / \mathrm{m}^{2} \\
(\mathrm{mean} \pm \mathrm{SD})\end{array}$ & $28.1 \pm 4.0$ & $26.0 \pm 2.4$ & 0.04 \\
\hline $\begin{array}{l}\text { Estimated fetal weight, } \\
\mathrm{g}(\text { mean } \pm \text { SD })\end{array}$ & $2,863 \pm 243$ & $2,754 \pm 169$ & 0.07 \\
\hline
\end{tabular}

Abbreviations: BMI, Body mass index; SD, standard deviation; $\mathrm{VO}_{2 \text { peak, }}$ Peak oxygen consumption. exercise phase, a reduction in the mean number of fetal movements, and an increase in the mean STV and in the median number of episodes of high variability. On the other hand, no differences were found in the frequency of transient decelerations or accelerations. Following the logistic regression analysis, the variables that remained associated with fetal bradycardia were physical fitness evaluated at the $28^{\text {th }}$ week, and maternal weight at the $36^{\text {th }}$ week.

There was a significant reduction in FHR during the treadmill-walking phase, falling from $137 \mathrm{bpm}$ at baseline to $98 \mathrm{bpm}$ during walking, with a frequency of bradycardia of $56 \%$ in the first 10 minutes of exercise and of $47 \%$ after 20 minutes, which may suggest nonreassuring fetal status. The decrease in the FHR was higher in overweight/obese pregnant women and was justified by the worse physical conditioning in this group, since physical conditioning remained a risk factor for fetal bradycardia after the regression analysis.

Nevertheless, two responses were identified that could have been influenced by fetal bradycardia in an attempt to compensate oxygenation at fetal regulation centers. The first was the increase in short-term variability, as shown by micro-oscillations, which can only be interpreted using the computed system. An increase from 7.9 milliseconds at baseline to 17.0 milliseconds during walking was found, showing that the fall in the FHR was accompanied by an extraordinary increase in variability, reflected in the measurement of short-term variability during the walking phase, which reached twice the level recorded at baseline. This

Table 2 Factors associated with fetal bradycardia during walking in the multiple logistic regression analysis

\begin{tabular}{|l|l|l|l|l|l|}
\hline & OR & $95 \% \mathrm{Cl}$ & Coefficient & SE & $p$-value \\
\hline Maternal weight at 36 weeks, kg & 4.07 & $1.15-14.4$ & 1.40 & 0.65 & 0.03 \\
\hline $\mathrm{VO}_{\text {2peak }}$ at 28 weeks & 0.25 & $0.06-0.98$ & -1.40 & 0.70 & 0.047 \\
\hline Constant & & & 1.76 & & \\
\hline
\end{tabular}

Abbreviations: $\mathrm{Cl}$, confidence interval; OR, odds ratio; SE, standard error.

This model predicts around $80 \%$ of the cases of fetal bradycardia during walking. 
increase in short-term variability was accompanied by an increase in the number of episodes of high variability.

Another interesting fact was a significant reduction in the number of fetal movements, which decreased from a mean of 29.2 movements/hour at baseline to 22 movements/hour during walking, which may reflect an energy-saving mechanism. ${ }^{21}$ The reduction in fetal movements may explain the reduced signal loss of fetal heart rate during walking. Notwithstanding, in the case of pregnant women exercising, a reduction in fetal perception may occur or there may be difficulty in activating the device, possibly hampering the recording of fetal movements, and this may represent a bias.

Two parameters are known to be important when monitoring fetal vitality: basal heart rate and its variability. ${ }^{18}$ Although a significant reduction was found in the FHR during the treadmill walking phase, a concomitant and significant increase in variability was recorded, demonstrating adequate oxygenation of the control centers of the brain, which gives strength to the hypothesis of a possible fetal compensatory mechanism.

The results of the present study differ from other findings, with the majority of studies reporting a lack of effect of exercise on FHR or tachycardia. ${ }^{4,6,22}$ Possible methodological differences may explain this divergence in results, as discussed below. One limitation of those other studies was the fact that the women were evaluated prior to and following exercise, but not during exercise.

One of the methodological strengths of the present study was the fact that the FHR was recorded continuously over the three different phases and, mainly, because the treadmillwalking phase was included in the analysis. Fetal heart rate monitoring during the exercise phase was of extreme importance, since it allowed the observation of the rapid change that occurred in some of the parameters evaluated immediately after the end of the walking phase, characterized by an increase in the FHR and in fetal movements. These results are in agreement with those found in a study conducted in sheep, when hemodynamic changes returned to pre-exercise levels within minutes following the end of exercise. ${ }^{8}$ It is obvious that in order to understand what actually occurs during the exercise phase, this phase must be monitored.

A study involving only three pregnant women reported results that are similar to those found in the present study. ${ }^{23}$ Those investigators reported a steep decline in the basal FHR, with bradycardia throughout the entire exercise period and a return to previous levels shortly after the exercise was stopped. On the other hand, a study involving 120 women at 16 to 39 weeks of pregnancy reported conflicting results. An increase in the FHR occurred at the $10^{\text {th }}$ minute of exercise and persisted until the $5^{\text {th }}$ minute of the recovery period. ${ }^{24}$ Analysis of the methodology used shows that FHR monitoring during the test was performed using real-time ultrasonography, and that the recording was not continuous, which may have affected negatively the quality of the interpretation. Another point that could be considered negative was the inclusion of subjects at such different stages of pregnancy, which may have had a negative effect on the measurement of the mean FHR. In the present study, this measurement was made at the $36^{\text {th }}$ week to avoid any effect of the immaturity of the nervous system on the results, which could have acted as a confounding factor.

Two papers on the subject have been published. The first involved 52 pregnant women divided into 2 groups: physically active and sedentary women. The women were in the $34^{\text {th }}$ week of pregnancy and were submitted to a test on a stationary bicycle at moderate intensity for a period of 20 minutes. The investigators reported an increase in the FHR immediately following exercise in both groups (active and sedentary women) ${ }^{25}$ It should be emphasized that the type of exercise chosen in this case was the stationary bicycle. The second paper evaluated alterations in the FHR and its variability during walking by 26 pregnant women who exercised regularly (30 minutes of aerobic exercise, 3 times a week) and 35 sedentary women. Despite the use of different methodology, mainly regarding FHR monitoring, the findings of those authors were similar: a reduction in HR and an increase in variation during the exercise. ${ }^{26}$

Most studies have included a control group of sedentary pregnant women. ${ }^{25,26}$ Conversely, since the main objective of the present study was to evaluate the acute effect of performing exercise on FHR, the baseline and recovery FHR data served as control. No control group of sedentary women was required, since the aim was not to compare the effect of exercise on sedentary and nonsedentary pregnant women. This will be the objective of the second phase of the present study. Another aspect is that there was a large gap in knowledge in relation to the practice of physical exercise and pregnancy, despite the fact that the practice of exercise during pregnancy is common. The recommendation to exercise during pregnancy is based on studies conducted in nonpregnant women; therefore, the first step was to demonstrate the safety of exercise in nonsedentary women.

Points that deserve discussion include the factors associated with bradycardia. Fetuses of heavier pregnant women were at a greater risk of bradycardia, whereas the risk was lower in the fetuses of women with better physical fitness levels. Very little is known in this respect, and further studies with appropriate designs are required to evaluate this subject adequately; however, conditions such as obesity and a sedentary lifestyle may affect venous return and cardiac output, which may explain this result. ${ }^{27,28}$ A study involving 12 physically active pregnant women evaluated uterine blood flow prior to and following moderate-intensity treadmill walking. The investigators concluded that the redistribution of uterine blood flow favoring muscles in response to hemodynamic stress provoked by exercise is less intense in women who undergo physical training during pregnancy. ${ }^{29}$

In the bivariate analysis, blood pressure measured in the final phase of exercise was shown to be associated with bradycardia, the risk being higher in women with lower systolic arterial pressure, possibly suggesting a greater risk of maternal hypotension leading to fetal bradycardia; nevertheless, the association did not remain statistically significant after controlling for potentially confounding variables.

As discussed above, various methodological issues may explain the differences in the results found. These issues refer 
particularly to the intensity of exercise, fitness level of the mother, gestational age at evaluation and, mainly, whether FHR was monitored or not during the exercise period.

In relation to the different methods currently available for the evaluation of fetal vitality, which include two-dimensional ultrasonography with or without Doppler velocimetry, conventional CTG or CTGc and fetal biophysical profile, ${ }^{21}$ the literature suggests varying evidence for each method. Nevertheless, all these methods are indicated for the measurement of FHR alone. Cardiotocography was selected for the present study because this method uses strips with which to establish the focus of auscultation, thus reducing the loss of focus during the performance of exercise.

Another point that deserves further discussion refers to the type of exercise. In the present study, exercise consisted of treadmill walking, whereas in the majority of the reported studies, exercise was performed on a stationary bicycle, which raises the following question: would the position of exercise during pregnancy, that is, seated or standing, exert different effects on the FHR? Which type of exercise is more common in clinical practice: walking or bicycling? Further studies are required to answer these questions, although walking is probably the most commonly practiced exercise, since it is inexpensive and accessible to the entire population, which is why it was selected for the present study.

Studies have shown that uterine blood flow does not change with exercise, ${ }^{30,31}$ but may drop steeply when the woman is in the supine position due to compression of the inferior vena cava, compromising venous return. ${ }^{32}$ Furthermore, a reduction of $\sim 30 \%$ in blood flow in the intervillous space occurs when women in the final phase of pregnancy move from the dorsal decubitus position, inclined at 45 degrees, or from the left lateral decubitus position to the supine position. In our study, the sudden drop in FHR after walking seems to suggest that the change from a supine position to an upright position may be responsible for the high percentage of bradycardia. However, we must emphasize that this effect was less evident among pregnant women with better fitness levels. However, the change in position during physical exercise is a limitation of the study and may constitute a bias.

Finally, as strong points of the study, the use of CTGc deserves particular mention, since this technique eliminated the possibility of any bias resulting from interobserver differences, allowing instant global assessment of variability in milliseconds (STV), which is impossible by visual analysis using conventional CTG, and this is the parameter that best relates to fetal $\mathrm{pH}$. In addition, the gestational age at which the test was performed was standardized, thus avoiding any interference caused by the immaturity of the central nervous system, a characteristic of earlier stages of pregnancy, in any of the outcome variables.

\section{Conclusion}

Although some questions remain to be answered, it is still feasible, however, to conclude that fetal well-being is preserved, since, although there is a significant reduction in FHR with a high percentage of bradycardia and a significant decrease in fetal movements during treadmill walking, this process is accompanied by an increase in variability, as shown by STV and episodes of high variability. Therefore, in low-risk pregnancies and healthy fetuses with the capacity to readapt to situations in which blood flow is reduced, supervised physical exercise proved to be safe. Notwithstanding, it is important to consider that other studies, particularly randomized controlled trials, are necessary to evaluate acute fetal hemodynamic modifications, including monitoring the phase of physical exercise and comparing several modalities of exercise in women with different nutritional status and levels of physical conditioning.

\section{Contributions}

The present study was conceived by Amorim M. and implemented by Melo A., with the analytical strategy developed in collaboration with Melo F., Barros E. S., Cruz H. L., and Souza A. S. R.. Amorim M. performed all the data handling and statistical analyses and is the guarantor. Silva J. L. P. contributed to the methodological discussions. Melo A. and Amorim M. drafted the first version of the paper, and all the coauthors revised the paper on several occasions.

\section{Conflicts of Interests}

The authors have no conflicts of interests to declare.

\section{Acknowledgments}

The authors are grateful to the teams at the healthcare units of the city of Campina Grande and to the collaborators at the Instituto de Pesquisa Professor Joaquim Amorim Neto (IPESQ, in the Portuguese acronym) for their support. The present study was supported by the National Council for Scientific and Technological Development ( $\mathrm{CNPq}$, in the Portuguese acronym) (Universal 480761/2008-6) and by the Paraíba Research Foundation (FAPESQ, in the Portuguese acronym) (PPSUS2009).

\section{References}

1 Clapp JF III. The effects of maternal exercise on fetal oxygenation and feto-placental growth. Eur J Obstet Gynecol Reprod Biol 2003; 110(Suppl 1):S80-S85. Doi: 10.1016/S0301-2115(03)00176-3

2 Brown J, Ceysens G, Boulvain M. Exercise for pregnant women with gestational diabetes for improving maternal and fetal outcomes. Cochrane Database Syst Rev 2017;6:CD012202. Doi: 10.1002/14651858.CD012202.pub2

3 Steegers EA, Buunk G, Binkhorst RA, Jongsma HW, Wijn PF, Hein PR. The influence of maternal exercise on the uteroplacental vascular bed resistance and the fetal heart rate during normal pregnancy. Eur J Obstet Gynecol Reprod Biol 1988;27(01):21-26. Doi: 10.1016/S0028-2243(88)80006-6

4 Silveira C, Pereira BG, Cecatti JG, Cavalcante SR, Pereira RI. Fetal cardiotocography before and after water aerobics during pregnancy. Reprod Health 2010;7:23. Doi: 10.1186/1742-4755-7-23

5 de Oliveria Melo AS, Silva JL, Tavares JS, Barros VO, Leite DF, Amorim MM. Effect of a physical exercise program during pregnancy on uteroplacental and fetal blood flow and fetal growth: a randomized controlled trial. Obstet Gynecol 2012;120(2 Pt 1):302-310. Doi: 10.1097/AOG.0b013e31825de592 
6 Tavares JS, Melo ASO, Leite SF, et al. Maternal-fetal acute responses to two moderate-intensity exercise types: a randomized clinical trial. Int Arch Med 2018;11:1-9. Doi: 10.3823/2558

7 da Silva JR Jr, Borges PS, Agra KF, Pontes IA, Alves JGB. Effects of an aquatic physical exercise program on glycemic control and perinatal outcomes of gestational diabetes: study protocol for a randomized controlled trial. Trials 2013;14:390. Doi: 10.1186/1745-6215-14-390

8 Lotgering FK, Gilbert RD, Longo LD. Exercise responses in pregnant sheep: oxygen consumption, uterine blood flow, and blood volume. JAppl Physiol 1983;55(03):834-841. Doi: 10.1152/ jappl.1983.55.3.834

9 Curet LB, Orr JA, Rankin HG, Ungerer T. Effect of exercise on cardiac output and distribution of uterine blood flow in pregnant ewes. JAppl Physiol 1976;40(05):725-728. Doi: 10.1152/ jappl.1976.40.5.725

10 Veille JC, Bacevice AE, Wilson B, Janos J, Hellerstein HK. Umbilical artery waveform during bicycle exercise in normal pregnancy. Obstet Gynecol 1989;73(06):957-960. Doi: 10.1097/00006250198906000-00010

11 Padhye N, Duan Z, Verklan M. Response of fetal heart rate to uterine contractions. Conf Proc IEEE Eng Med Biol Soc 2004; 6:3953-3955. Doi: 10.1109/IEMBS.2004.1404104

12 Carpenter MW, Sady SP, Hoegsberg B, et al. Fetal heart rate response to maternal exertion. JAMA 1988;259(20):3006-3009. Doi: $10.1001 /$ jama.1988.03720200028028

13 ACOG Committee Opinion No. 650: physical activity and exercise during pregnancy and the postpartum period. Obstet Gynecol 2015; 126(06):e135-e142. Doi: 10.1097/AOG.0000000000001214

14 Chasan-Taber L, Schmidt MD, Roberts DE, Hosmer D, Markenson G, Freedson PS. Development and validation of a pregnancy physical activity questionnaire. Med Sci Sports Exerc 2004;36 (10):1750-1760. Doi: 10.1249/01.MSS.0000142303.49306.0D

15 Di Tommaso M, Martello G, Kanninen T, Perelli F, Iannuzzi L, Sisti G. Computerized cardiotocography analysis: comparison among several parental ethnic origins. Rev Bras Ginecol Obstet 2016;38 (12):589-592. Doi: 10.1055/s-0036-1594288

16 Fox SM III, Naughton JP, Haskell WL. Physical activity and the prevention of coronary heart disease. Ann Clin Res 1971;3(06): 404-432

17 Borg GA. Psychophysical bases of perceived exertion. Med Sci Sports Exerc 1982;14(05):377-381

18 American College of Obstetricians and Gynecologists. ACOG Practice Bulletin No. 106: Intrapartum fetal heart rate monitoring: nomenclature, interpretation, and general management principles. Obstet Gynecol 2009;114(01):192-202. Doi: 10.1097/AOG.0b013e 3181aef106

19 Institute of Medicine. National Research Council. Committee to Reexamine IOM Pregnancy Weight Guidelines; Rasmussen KM,
Yaktine AL, eds. Weight Gain During Pregnancy: Reexamining the Guidelines. Washington, DC: National Academies Press; 2009

20 Mottola MF, Davenport MH, Brun CR, Inglis SD, Charlesworth S, Sopper MM. VO2peak prediction and exercise prescription for pregnant women. Med Sci Sports Exerc 2006;38(08):1389-1395. Doi: 10.1249/01.mss.0000228940.09411.9c

21 American College of Obstetricians and Gynecologists. Practice bulletin no. 145: antepartum fetal surveillance. Obstet Gynecol 2014; 124(01):182-192. Doi: 10.1097/01.AOG.0000451759.90082.7b

22 Skow RJ, Davenport MH, Mottola MF, et al. Effects of prenatal exercise on fetal heart rate, umbilical and uterine blood flow: a systematic review and meta-analysis. Br J Sports Med 2019;53 (02):124-133. Doi: 10.1136/bjsports-2018-099822

23 Artal R, Romem Y, Paul RH, Wiswell R. Fetal bradycardia induced by maternal exercise. Lancet 1984;2(8397):258-260. Doi: 10.1016/s0140-6736(84)90301-5

24 Clapp JF III, Little KD, Capeless EL. Fetal heart rate response to sustained recreational exercise. Am J Obstet Gynecol 1993;168(1 Pt 1):198-206. Doi: 10.1016/s0002-9378(12)90914-x

25 Barakat R, Ruiz JR, Rodríguez-Romo G, Montejo-Rodríguez R, Lucia A. Does exercise training during pregnancy influence fetal cardiovascular responses to an exercise stimulus? Insights from a randomised, controlled trial. Br J Sports Med 2010;44(10): 762-764. Doi: 10.1136/bjsm.2009.062547

26 May LE, Glaros A, Yeh HW, Clapp JF III, Gustafson KM. Aerobic exercise during pregnancy influences fetal cardiac autonomic control of heart rate and heart rate variability. Early Hum Dev 2010;86(04):213-217. Doi: 10.1016/j.earlhumdev.2010.03.002

27 Pivarnik JM, Mauer MB, Ayres NA, Kirshon B, Dildy GA, Cotton DB. Effects of chronic exercise on blood volume expansion and hematologic indices during pregnancy. Obstet Gynecol 1994;83(02):265-269

28 Clark SL, Cotton DB, Pivarnik JM, et al. Position change and central hemodynamic profile during normal third-trimester pregnancy and post partum. Am J Obstet Gynecol 1991;164(03):883-887. Doi: 10.1016/s0002-9378(11)90534-1

29 Clapp JF III, Stepanchak W, Tomaselli J, Kortan M, Faneslow S. Portal vein blood flow-effects of pregnancy, gravity, and exercise. Am JObstet Gynecol 2000;183(01):167-172. Doi: 10.1067/mob.2000.105902

30 Pigatto C, Santos CM, Santos WM, et al. [Effects of physical exercise on the fetal hemodynamic parameters]. Rev Bras Ginecol Obstet 2014;36(05):216-221. Doi: 10.1590/S0100-7203201400050006

31 Kauppila A, Koskinen M, Puolakka J, Tuimala R, Kuikka J. Decreased intervillous and unchanged myometrial blood flow in supine recumbency. Obstet Gynecol 1980;55(02):203-205

32 Jeffreys RM, Stepanchak W, Lopez B, Hardis J, Clapp JF III. Uterine blood flow during supine rest and exercise after 28 weeks of gestation. BJOG 2006;113(11):1239-1247. Doi: 10.1111/j.14710528.2006.01056.x 